\title{
Effects of Tartrazine on Neural Tube Development in the Early Stage of Chicken Embryos
}

\author{
Aysegul OZDEMIR OVALIOGLU1', Talat Cem OVALIOGLU1', Gokhan CANAZ², Aysegul ESEN AYDIN", \\ Sema ARSLAN ${ }^{3}$, Mehmet SAR ${ }^{4}$, Erhan EMEL ${ }^{1}$ \\ ${ }^{1}$ Bakirkoy Research and Training Hospital for Neurology, Neurosurgery and Psychiatry, Department of Neurosurgery, Istanbul, Turkey \\ ${ }^{2}$ Arnavutkoy State Hospital, Department of Neurosurgery, Istanbul, Turkey \\ ${ }^{3}$ Marmara University, Department of Biochemistry, Istanbul, Turkey \\ ${ }^{4}$ Bakirkoy Dr. Sadi Konuk Research and Training Hospital, Department of Pathology, Istanbul, Turkey
}

Corresponding author: Gokhan CANAZ gokhancanaz@gmail.com

\section{ABSTRACT}

AIM: To investigate the effects of tartrazine exposure on neural tube development, in early stage chicken embryos.

MATERIAL and METHODS: A total of 120 fertilized specific pathogen-free chicken eggs were divided into 4 equal groups (groups 1-4). After 30 hours of incubation, the eggs, except for the Group 1 (control group), were opened under $4 \mathrm{X}$ optical magnification. Group 2 was administered physiological saline. Group 3 was administered a middle dose of tartrazin (4.5 mg/kg) at a volume of 20 $\mu \mathrm{L}$ by the in ovo method, and group 4 was administered a high dose of tartrazine $(7.5 \mathrm{mg} / \mathrm{kg})$ using the same process. Incubation was continued until the end of the $72^{\text {nd }}$ hour; all embryos were then removed from the eggs and histopathologically examined.

RESULTS: Of the 120 embryos incubated, normal development and the closed neural tubes were shown in all embryos in group 1; 23 in group 2; 19 in group 3 and; only 9 in group 4. Open neural tubes were found in; 4 embryos in group 2; 5 embryos in group 3 and; 13 embryos in group 4 . The neural tube closure defect was found to be significantly higher in group 4 compared to the other groups $(\mathrm{p}<0.01)$.

CONCLUSION: Based on our data, tartrazine, as one of the widely used food coloring agent, was seen to cause a neural tube defect in the chicken embryo model.

KEYWORDS: Tartrazine, Neural tube defect, Chicken embryo, Food additive, Spina bifida

ABBREVIATIONS: ADI: Acceptable daily intake, E 107: Tartrazine, NTD: Neural tube defects, SPSS: Statistical package for the social sciences

\section{INTRODUCTION}

$\mathrm{N}$ eural tube defects (NTD) occur as a result of disruption of the closure process of the neural tube between the $3^{\text {rd }}$ and $4^{\text {th }}$ weeks of gestation $(7,18)$. It is well-known that neural tube closure is a vulnerable process, and therefore, external factors play an important rolein the etiology of NTD's.
Various studies on these factors including, drugs, maternal diabetes, food additives, and air pollution, are well reported in the literature $(3,11,20,21)$. These studies are important because, the majority of the time, it is possible to avoid hazardous conditions by altering lifestyles or by enacting a change current regulations.
Aysegul OZDEMIR OVALIOGLU (1) : 0000-0003-2292-3132 Talat Cem OVALIOGLU Gokhan CANAZ (1D) : 0000-0003-1682-9641
Aysegul ESEN AYDIN (1) : 0000-0001-7444-8156 (1) : $0000-0003-0658-9306$
Sema ARSLAN (D) : 0000-0003-2205-0415

Mehmet SAR (1) : 0000-0003-1445-6685 Erhan EMEL (D) : 0000-0002-0584-9164 
It is well accepted that coloring food can make it more aesthetically and psychologically attractive. Food coloring agents are routinely used to streng then the weak natural color, and to give color to colorless foods. Thus, the addition of food coloring serves to make food more attractive and can mask low-quality food. Some coloring agents are derived from natural substances, such as carotene or chlorophyll; others are synthetically obtained, such as allura red, erythrosine, and tartrazine (24).

Tartrazine (E 107) is a yellow, water-soluble, anionic azodye, that is used to give yellow color to foods. Previous studies investigating tartrazine have reported a wide-range of side effects, including endocrine diseases to hematologic pathologies $(1,23,24)$. Even though a few studies found that no developmental effects were observed in the fetus, we aimed to investigate the possible effects of tartrazine exposure on neural tube development.

\section{MATERIAL and METHODS}

This study was conducted in cooperation with the Neurosurgical Unit Research Laboratory of Bakirkoy Prof. Dr. Mazhar Osman Mental Health and Neurological Diseases Training and
Research Hospital. Fertilized, specific pathogen-free gallus chicken eggs were obtained from the Poultry Research Institute, Ankara, Turkey.

\section{Incubation and Injection}

One hundred and twenty fertile, specific non-pathogenic, domestic fowl eggs (Atabey ${ }^{\circledR}$, Gallus gallus, Poultry Research Institute, Ankara, Turkey) were used in the study. The eggs were incubated at $37.5^{\circ} \mathrm{C}$ and $75 \%$ humidity. At the eighth stage of the Hamburger and Hamilton classification, the eggs were sterilized with $70 \%$ alcohol and taped was applied on the outer shell. A window was opened on the eggshell. Using a sterile Hamburger ${ }^{\circledR}$ syringe, $20 \mu \mathrm{L}$ of fluid was administrated sub-blastodermically (Figure 1). The holes were closed with a drape, and then the eggs were placed back into the incubator. After 72 hours of incubation (Hamburger Hamilton stage 12), the eggs were reopened. The viability of the embryos was assessed by the presence of a heartbeat. The embryos were transferred into a petri dish by dissecting, microsurgically, along the allantoic stalk (Figure 2A, B). All of the embryos were examined under a microscope (Leica DM 4000 - Germany). Results were analyzed in terms of neural tube closure (Figure $3 A, B)$.
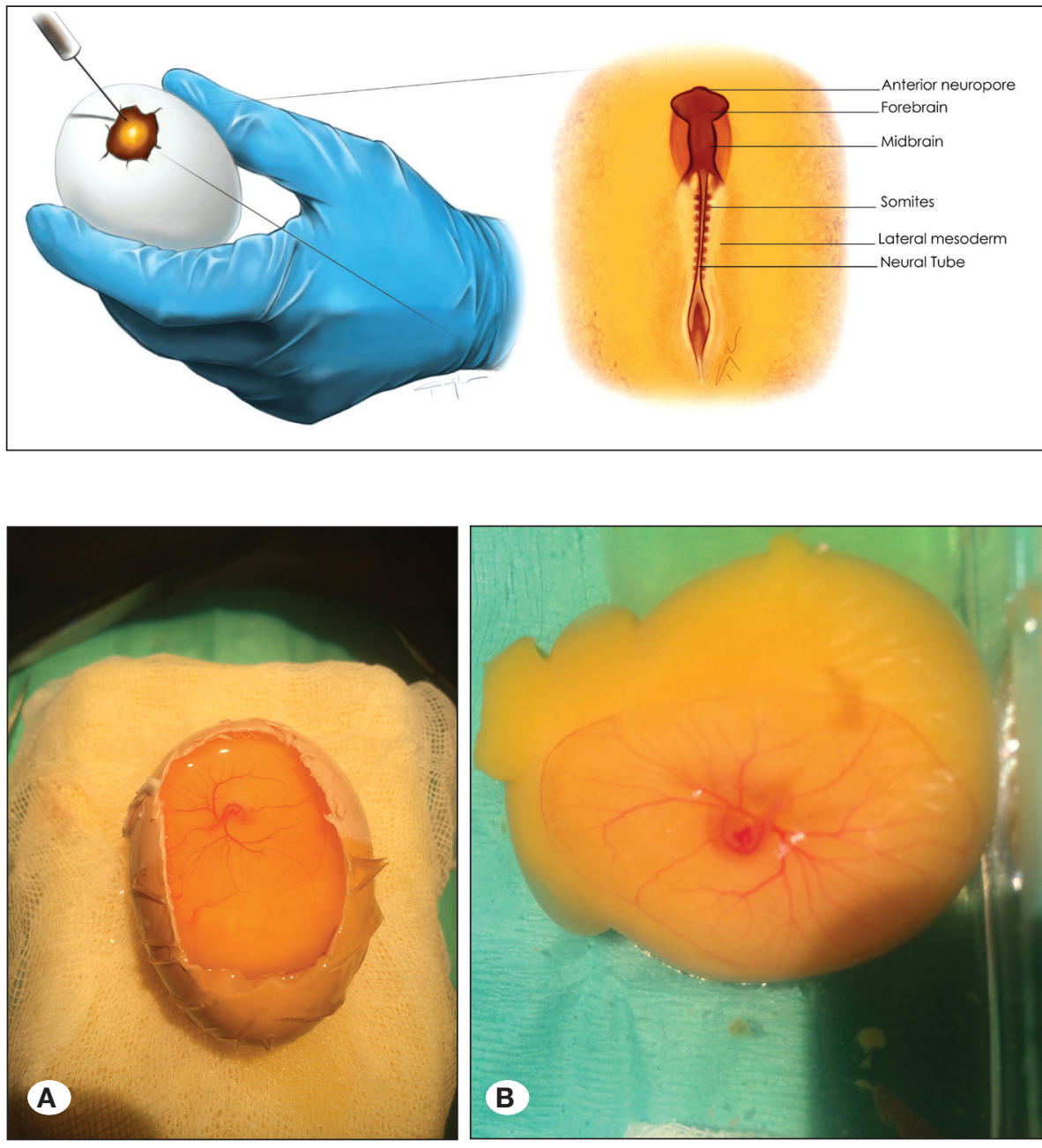

Figure 1: Illustration of the subblastodermic injection and the features of stage 9 chicken embryo. (Hamburger Hamilton classification). 


\section{Study Groups}

Eggs were assigned to one of four groups. Three eggs were sacrificed in the determination of stage. For this study, we used four experimental groups (2-4), and a single control group (Group 1), each containing 30 eggs/embryos (Table I). At the end of the $30^{\text {th }}$ hour of the incubation, each egg in group $2(n=30)$ was injected with $0.01 \mathrm{ml}$ of saline. Eggs in group 3 were injected with $0.02 \mathrm{ml}$ of a solution containing $450 \mu \mathrm{g}$ of tartrazine (middle dose). Eggs in group 4 were injected with $0.02 \mathrm{ml}$ of a solution containing $750 \mu \mathrm{g}$ of tartrazine (high dose).

\section{Pathological Evaluation}

Formalin-fixed, embryo tissue samples were embedded in paraffin. Briefly, the embryos were dehydrated using ethanol

Table I: Distribution of Tartrazin (E102) dosages in Different Groups

\begin{tabular}{cc}
\hline Group & Dose \\
\hline 1 & Closed \\
\hline 2 & Control group, $0.01 \mathrm{ml}$ of saline \\
\hline 3 & $4.5 \mathrm{mg} / \mathrm{kg}$ Tartrazine \\
\hline 4 & $7.5 \mathrm{mg} / \mathrm{kg}$ Tartrazine \\
\hline
\end{tabular}

solutions. After the dehydration, the embryos were incubated in xylene and then transferred into a paraffin embedding mixture. Tissue sections ( $5 \mu \mathrm{m}$ thickness) were taken. Afterwhich, haematoxylin-eosin solution was applied to the tissue sections. Samples were evaluated under the microscope and assessed for decomposition of somite pairs and neural tube continuity.

\section{Statistical Analysis}

Statistical evaluations were conducted using the Statistical Package for the Social Sciences (SPSS) V22.0 for Windows. The chi-square test was used to analyze group comparisons. A $p$-value of $\leq 0.05$ was accepted as statistically significant.

\section{RESULTS}

In Group 1, two embryos (6.6\%) were undeveloped and 28 embryos (95\%) were intact. In Group 2, 3 embryos (10\%) were undeveloped, 4 embryos developed NTD (13\%) and 23 embryos (76.6\%) were intact ( $p=0.3985)$. In Group 3, 5 embryos (16.6\%) had NTD, 6 embryos (20\%) were undeveloped, and 19 embryos (63\%) were intact ( $p=0.1455)$. In Group 4, 13 embryos (43.3\%) had NTD, 8 embryos (26.6\%) were undeveloped, and 9 embryos $(30 \%)$ were intact $(p=0.0006)$ (Table II). These results were interpreted as a dose-dependent effect because the significance observed in the higher dose group.

Table II: Number of Embryos with Neural Tube Closure or Developmental Defects

\begin{tabular}{ccccc}
\hline Group & Intact & Neural tube defect & Undeveloped & $\mathbf{p}$ \\
\hline 1 & 28 & 0 & 2 & $>0.05$ \\
\hline 2 & 23 & 4 & 3 & 0.3985 \\
\hline 3 & 19 & 5 & 6 & 0.1455 \\
\hline 4 & 9 & 13 & 8 & $\mathbf{0 . 0 0 0 6}$ \\
\hline
\end{tabular}

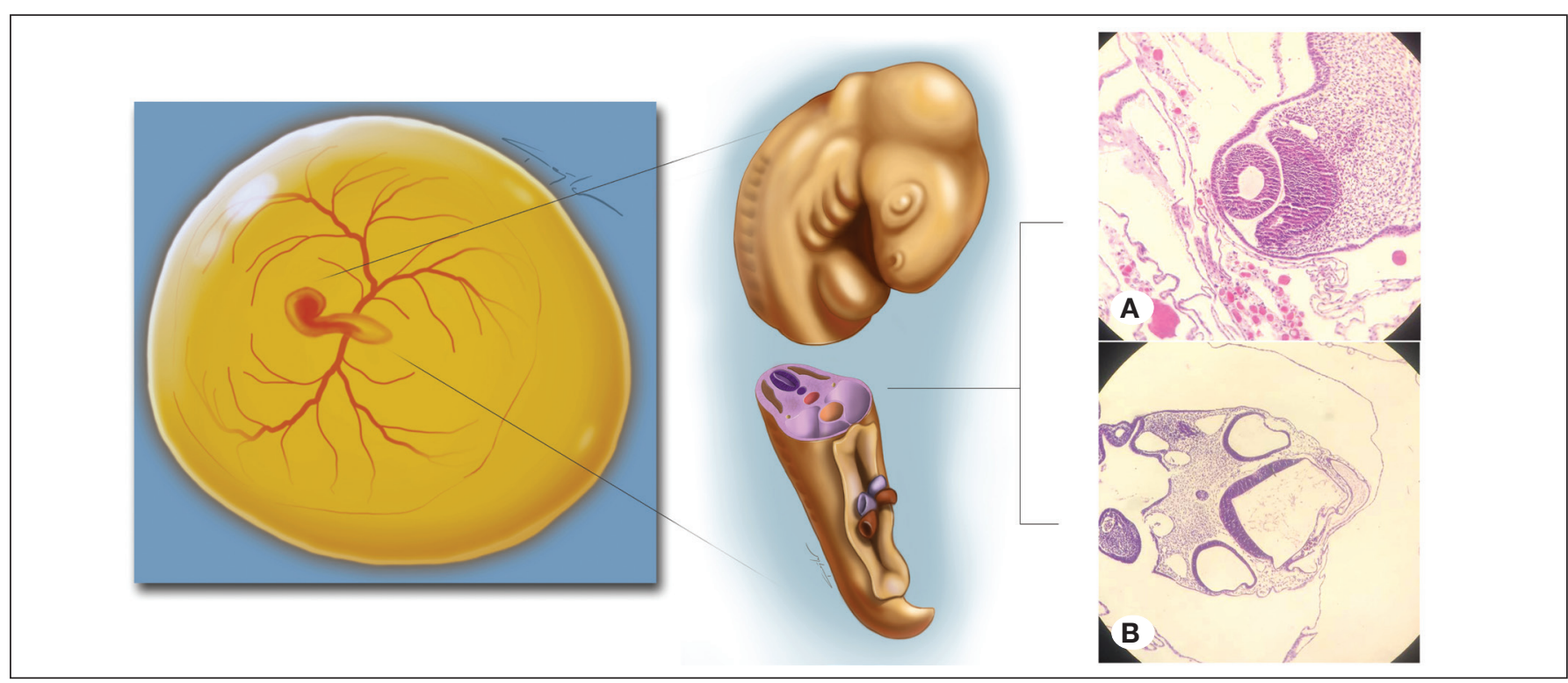

Figure 3: Illustration of re-opened embryo at stage 18 and the light microscope images of closed (A), and opened (B) neural tubes (HEx100) (Hamburger - Hamilton classification). 


\section{DISCUSSION}

The worldwide incidence of NTD's ranges from 1 to 10/1000 births $(11,12,28)$. Turkey has an average incidence of 3-5.8/1000 births (25). Importantly, folic acid deficiency and anti-epileptic drug use are known to be the most important external factors in NTD's $(7,11)$. Studies shown that maternal age, maternal diabetes, exposure to chemicals, and air pollution also have negative effects on neural tube closure $(3,18,20)$. It is almost impossible for a pregnant woman to avoid certain chemicals; especially when considering recent use rates of food additives and daily exposure. This is of particular importance in the first three weeks of gestation. Because pregnancy tests become positive after two weeks of gestation, many woman are unaware of a pregnancy status during this critical period of neural tube closure.

Food additives are used for flavoring, preservation, coloring, texturizing, and nutritive additions. Some coloring agents are derived from natural pigments, like carotene or chlorophyll. However, coloring agents such as tartrazine, erythrosine, allura red are synthetically produced (10). Acceptable daily intake (ADI) of Tartrazine, established by the European food safety authority, is $7.5 \mathrm{mg} / \mathrm{kg}$ bw/day; however, the use of this additive is banned in Norway (6). In our study, we used the ADI dose as a high dose and demonstrated significant effects. Tartrazine is widely used as a yellow color additive in soft drinks, cotton candy, cereals, flavored corn chips, soups jams, noodles, sauces, etc. Additionally, it is found in soaps, cosmetic products, and crayons. Tartrazine is a nitrous derivate (azo class), and when consumed, it is reduced into an aromatic amine, a highly sensitized metabolite, in the body (10). Aromatic amines are oxidized to $\mathrm{N}$-hydroxy derivates by p450 enzymatic system (5). It has been suggested that this mechanism is responsible for the side effects of tartrazine exposure.

Numerous studies in the have shown the side effects of tartrazine. These effects range from carcinogenic to neurobehavioral. It has also been suggested that tartrazine may cause an allergic reaction in atopic individuals; however, this has been the most debated side effect of tartrazine in the literature $(2,13,17)$. The potential side effects in asthmatic children is especially debated.

In multiple studies performed in rats, a significant rise in ALT, AST, and ALP levels was shown even with a low dose of tartrazine $(1,14,24)$. Besides enzymatic effects, macroscopic effects were reported in the liver, including hemorrhaging reported by Himiri et al. (9). Visweswaran and Krishnamoorthy reported on the mutagenic effect of tartrazine (26). Whereas Tanaka reported the neurobehavioral effects on rats on high doses but stated that "...it is not likely to cause similar effects on humans", because the effective dose was much higher than ADI dose (23). Contrary to this, Rowe and Rowe, and Ward reported that some children might show hyperactivity after tartrazine with consumption of an average dose $(19,27)$.

In another study, evaluating the neurotoxic effect of tartrazine, a significant decrease in gamma-aminobutyric acid, dopamine, and serotonin levels were shown; in addition to an increase in the number of apoptotic cells in the cerebral cortex (15).

Previous studies examining the effects of tartrazine on development in rats reported that tartrazine showed no effect on development, which differ from our results $(4,22)$. However, a more recent study investigating the effects of food additives' on various organisms, including zebrafish, reported that $20 \%$ of the embryos showed developmental defects due to tartrazine exposure (16). An additional recent study, investigating rats, also demonstrated various embryotoxic and teratogenic outcomes (8). These recent results found that the potential role of tartrazine exposure needs further investigation.

\section{CONCLUSION}

Our study demonstrated that tartrazine causes NTD, at the ADI dose, in the chicken model of embryo development. Since this is the first study to demonstrate the effect of tartrazine on neural tube development, the potential mechanism of disruption on neural tube closing needs to be investigated. Among many other potential side effects, recent studies have suggested tartrazine may influence other the developmental processes; these potential effects also warrant further investigation.

\section{ACKNOWLEDGMENTS}

We want to thank "Cura Canaz Medical Arts (www. ccmedicalarts.com)" for medical illustrations.

\section{REFERENCES}

1. Amin KA, Abdel Hameid $2^{\text {nd }} \mathrm{H}$, Abd Elsttar $\mathrm{AH}$ : Effect of food azo dyes tartrazine and carmoisine on biochemical parameters related to renal, hepatic function and oxidative stress biomarkers in young male rats. Food Chem Toxicol 48(10):2994-2999, 2010

2. Ardern KD, Ram FS: Tartrazine exclusion for allergic asthma. Cochrane Database Syst Rev 2001(4):CD000460, 2001

3. Canaz H, Alatas I, Canaz G, Gumussuyu G, Cacan MA, Saracoglu A, Ucar BY: Surgical treatment of patients with myelomeningocele-related spine deformities: Study of 26 cases. Childs Nerv Syst 34(7):1367-1374, 2018

4. Collins TF, Black TN, Brown LH, Bulhack P: Study of the teratogenic potential of FD \& C Yellow No. 5 when given by gavage to rats. Food Chem Toxicol 28(12):821-827, 1990

5. Demirkol O, Zhang X, Ercal N: Oxidative effects of Tartrazine (CAS No. 1934-21-0) and New Coccin (CAS No. 2611-82-7) azo dyes on $\mathrm{CHO}$ cells. J Verbr Lebensm 7:229-236, 2012

6. European Food Safety Authority (EFSA): Scientific Opinion on the re-evaluation of Tartrazine (E102). EFSA Journal 7(11):1331, 2009

7. Frey L, Hauser WA: Epidemiology of neural tube defects. Epilepsia 44 Suppl 3:4-13, 2003

8. Hashem MM, Abd-Elhakim YM, Abo-El-Sooud K, Eleiwa MME: Embryotoxic and teratogenic effects of tartrazine in rats. Toxicol Res 35(1):75-81, 2019 
9. Himiri I, Bellahcen S, Souna F, Belmekki F, Aziz M, Bnouham M, Berkia Z, Mekhfi H, Saaluri E: A 90-day oral toxicity study of tartrazine, a synthetic food dye, in wister rats. International Journal of Pharmacy and Pharmaceutical Sciences 3:159169, 2011

10. Kamal A, Fawzia S: Toxicological and safety assessment of tartrazine as a synthetic food additive on health biomarkers: A review. African Journal of Biotechnology 17:139-149, 2018

11. Kaufman BA: Neural tube defects. Pediatr Clin North Am 51:389-419, 2004

12. Lamers Y, MacFarlane AJ, O'Connor DL, Fontaine-Bisson B: Periconceptional intake of folic acid among low-risk women in Canada: Summary of a workshop aiming to align prenatal folic acid supplement composition with current expert guidelines. Am J Clin Nutr 108:1357-1368, 2018

13. Mehedi N, Mokrane N, Alami O, Ainad-Tabet S, Zaoui C, Kheroua O, Saidi D: A thirteen week ad libitum administration toxicity study of tartrazine in Swiss mice. African Journal of Biotechnology 12(28):4519-4529, 2013

14. Mekkawy $\mathrm{H}$, Ali M, El-Zawahry A: Toxic effect of synthetic and natural food dyes on renal and hepatic functions in rats. Toxicology Letters 95:155-155, 1998

15. Mohamed AA, Galal AA, Elewa YH: Comparative protective effects of royal jelly and cod liver oil against neurotoxic impact of tartrazine on male rat pups brain. Acta Histochemica 117:649-658, 2015

16. Motta CM, Simoniello P, Arena C, Capriello T, Panzuto R, Vitale E, Agnisola C, Tizzano M, Avallone B, Ferrandino I: Effects of four food dyes on development of three model species, Cucumis sativus, Artemia salina and Danio rerio: Assessment of potential risk for the environment. Environmental Pollution 253:1126-1135, 2019

17. Rajan JP, Simon RA, Bosso JV: Prevalence of sensitivity to food and drug additives in patients with chronic idiopathic urticaria. J Allergy Clin Immunol Pract 2(2):168-171, 2014
18. Ray JG, Wyatt PR, Vermeulen MJ, Meier C, Cole DE: Greater maternal weight and the ongoing risk of neural tube defects after folic acid flour fortification. Obstetrics and Gynecology 105:261-265, 2005

19. Rowe KS, Rowe KJ: Synthetic food coloring and behavior: A dose response effect in a double-blind, placebo-controlled, repeated-measures study. J Pediatr 125:691-698, 1994

20. Shaw GM, Quach T, Nelson V, Carmichael SL, Schaffer DM, Selvin S, Yang W: Neural tube defects associated with maternal periconceptional dietary intake of simple sugars and glycemic index. Am J Clin Nutr 78:972-978, 2003

21. Simsek H, Colak A, Kaya S, Kutlay M, Cetinkal A, Haholu A, Demircan MN: The effects of Diesel exhaust particles on neural tube development in the early stage chicken embryo. Turk Neurosurg 22:77-82, 2012

22. Sobotka TJ, Brodie RE, Spaid SL: Tartrazine and the developing nervous system of rats. J Toxicol Environ Health 2(5):1211-1220, 1977

23. Tanaka T: Reproductive and neuro behavioural toxicity study of tartrazine administered to mice in the diet. Food and Chemical Toxicology 44:179-187, 2006

24. Tawfek N, Amin H, Abdalla A, Fargali S: Adverse effects of some food additives in adult male albino rats. Current Science International 4:525-537, 2015

25. Tuncbilek E, Boduroglu K, Alikasifoglu M: Neural tube defects in Turkey: Prevalence, distribution and risk factors. Turkish Journal of Pediatrics 41:299-305, 1999

26. Visweswaran B, Krishnamoorthy G: Oxidative stress by tartrazine in the testis of Wistar rats. Journal of Pharmacy and Biological Sciences 2:44-49, 2012

27. Ward NI: Assessment of chemical factors in relation to child hyperactivity. Journal of Nutritional \& Environmental Medicine 7:333-342, 1997

28. Yerby MS: Clinical care of pregnant women with epilepsy: Neural tube defects and folic acid supplementation. Epilepsia 44 Suppl 3:33-40, 2003 